Comparison of postneonatal mortality in social classes I and $V$ over time

\begin{tabular}{|c|c|c|c|c|c|c|c|}
\hline \multirow{3}{*}{$\begin{array}{l}\text { Social } \\
\text { class }\end{array}$} & \multicolumn{4}{|c|}{1970 Classification of occupations } & \multicolumn{3}{|c|}{1980 Classification of occupations } \\
\hline & \multirow{2}{*}{$\begin{array}{c}\begin{array}{c}\text { Decennial } \\
\text { supplement }\end{array} \\
1970-2\end{array}$} & \multicolumn{3}{|c|}{ DH3 series } & \multicolumn{3}{|c|}{ DH3 series } \\
\hline & & $1975-6$ & $1977-8$ & 1979 & 1979 & $1980-1$ & $1982-3$ \\
\hline I & $\begin{array}{r}2 \cdot 9 \\
13 \cdot 1\end{array}$ & $\begin{array}{l}2.8 \\
8.5\end{array}$ & $\begin{array}{l}2.9 \\
7.6\end{array}$ & $\begin{array}{l}3 \cdot 2 \\
9 \cdot 1\end{array}$ & $\begin{array}{l}3 \cdot 3 \\
8 \cdot 1\end{array}$ & $\begin{array}{l}3 \cdot 2 \\
6.6\end{array}$ & $\begin{array}{l}2 \cdot 5 \\
6 \cdot 2\end{array}$ \\
\hline Ratio & $4 \cdot 5$ & $3 \cdot 0$ & $2 \cdot 6$ & $2 \cdot 8$ & $2 \cdot 5$ & $2 \cdot 1$ & $2 \cdot 5$ \\
\hline
\end{tabular}

Sources: Decennial supplement on occupational montality, 1970-72. London: HMSO, 1978. OPCS Series SMPS No 41 and DH3 Nos 7, 9, 13-15. London: HMSO.

of classifying these social class data in 1979. The table above extends the table presented by Pharoah and Macfarlane to 1983 and includes OPCS 1979 bridge coded data. This suggests that over half the fall in the ratio between 1975-6 and 1982-3 may be ascribed to the change in classification.

Thus, although there has undoubtedly been a real reduction in the class ratio over time, the magnitude of the improvement is not as great as $\mathrm{Dr}$ Gordon's figures imply. One possible reason for the improvement that has taken place, suggested by Pharoah and Macfarlane, could be that developments in neonatal care in the 1970 s may have delayed some deaths, causing them to be counted in the postneonatal period. If this effect were greatest in social groups or health areas with the best medical care the paradoxical result would be a narrowing of postneonatal gradients.

The lesson from all this is that, in focusing attention on health indices based on only a narrow part of any set of continuous data, there is always a risk of serious misinterpretations. This applies equally to the measurement of class gradients and of survival from birth.

Social Statistics Research Unit,

The City University,

London $\mathrm{ECIV} O \mathrm{HB}$

1 Adelstein AM, Macdonald-Davies IM, Weatherall JAC. Perinatal and infant mortality: social and biological factors 1975-77. London: HMSO, 1980. (OPCS series SMPS No 41.)

2 Pharoah POD, Macfarlane A. Recent trends in post neonatal mortality. In: Studies in sudden infant death. London: HMSO 1982: 1-8. (OPCS series SMPS No 45.)

SIR,-Although Dr R R Gordon is correct in his observation that according to published statistics social class differences in postneonatal mortality narrowed between $1970-2$ and 1983, the news is not as good as his comments imply.

Firstly, as Peter Goldblatt points out, the data for $1970-2$ were derived in a different way from those from 1975 onwards and the way of classifying fathers' occupations according to social class changed in 1979. In addition, even when looking at the data for 1975 onwards, which apply to babies born within marriage, it must be remembered that this group decreased from $90.9 \%$ of all births in 1975 to $82.6 \%$ in 1984 . $^{1}$

The data shown in the figure have not been adjusted to allow for these differences, but they illustrate the most notable feature of the postneonatal mortality rate for recent years-its failure to decline. ${ }^{23}$ Postneonatal mortality does not seem to have declined since 1970-2 in babies of men in manual occupations. There has also been very little decline since 1979 in death rates among babies with fathers in non-manual occupations. In particular, death rates among babies with fathers in unskilled occupations have fluctuated considerably since 1979. Similar fluctuations can be seen in the postneonatal death rates among babies born outside marriage, which are not shown in the figure.

For England and Wales as a whole postneonatal mortality rates remained almost constant from 1976 to 1982. ${ }^{3}$ Although there were small decreases in 1983 and 1984, there was no sign of further decline in 1985.

A similar levelling off has been observed in many other developed countries. ${ }^{45}$ Furthermore, there is a narrowing of differences between countries similar to that which, as Dr Gordon points out, has occurred commitment to action. Series DH3. London: OPCS.

Postneonatal mortality by father's social class, England and Wales
5 Starfield B. Postneonatal mortality. Annu Rev Public Health 1985;6:21-40.

Office of Population Censuses and Surveys. Mortality statistics: childhood, 1984. London: HMSO, 1986. (Series DH3 No 16.) Office of Population Censuses and Surveys. Sudden infant death syndrome 1983, 1984. London: OPCS, 1985. (OPCS Monitor DH3 85/4.)

8 Pharoah POP, Macfarlane AJ. Recent trends in infant mortality. In: Studies in sudden infant death. London: HMSO, 1982:1-8. (Studies on medical and population subjects No 45.)

9 Arneil GC, Brooke H, Gibson AAM, Harvic A, McIntosh H, Patrick WJA. National post perinatal infant mortality and cot death study, Scotland 1981-2. Lancet 1985; i:740-3.

\section{Angina pectoris-like pains provoked by intravenous adenosine}

between English regions. He is, however, incorrect in saying that about $90 \%$ of deaths from 1 month to 1 year are due to either congenital anomalies or the sudden infant death syndrome. In $1984,21 \%$ of these deaths were due to congenital malformations and $41 \%$ to the sudden infant death syndrome. ${ }^{6}$ Adding the furthe $6 \%$, including a few attributed to congenital malformations, where "sudden infant death" was men tioned elsewhere on the death certificate ${ }^{7}$ means that these two groups of conditions accounted for just ove two thirds of postneonatal deaths.

The levelling off of postneonatal mortality rates is difficult to interpret. It may reflect to some extent the longer survival of babies receiving neonatal intensive care, but other factors may play a part. ${ }^{89}$

Meanwhile, although social class is a crude measure, it does point to the existence of consider able differences in mortality between the most and least favoured sectors of the population in mortality, not only in the postneonatal period but also in the perinatal period and throughout the first year of life. Clearly the analyses in the Black report need to be updated and extended, but this does no invalidate its central message. Further research should therefore be undertaken in the context of

Alison Macfarlane

National Perinatal Epidemiology Unit,

Radcliffe Infirmary,

Oxford OX2 6HE

Office of Population Censuses and Surveys. Birth statistics. Series FM1. London: OPCS.

2 Office of Population Censuses and Surveys. Occupational mortality. Decennial supplement 1970-2. London: HMSO, 1978. (Series DS No 1.)

3 Office of Population Censuses and Surveys. Mortality statistics.

Kaminski M, Bouvier-Colle MH, Blondel B. Mortalité des jeunes dans les pays de la Communauté Européene. Paris: Doin, les editions INSERM, 1986
SIR, - We read with interest the proposition of Dr Christer Sylvén and colleagues (26 July, p 227) that adenosine may protect against myocardial ischaemia by inducing the warning symptom of angina. They base this hypothesis on data confirming that intravenous boluses of adenosine can cause angina-like pain. We observe such retrosternal pain associated with tightness in the arms, neck, or epigastrium in only about half of our subjects, perhaps because we titrate the dosage individually: we did not so lightly disregard the potential pathophysiological significance of the symptoms as Dr Sylvén and colleagues suggest. We find, however, that similar sensations of tightness in the arms, neck, or epigastrium are induced when adenosine is infused into the aortic arch. ${ }^{1}$ Since the half life of adenosine is probably less than 10 seconds, ${ }^{2}$ this might suggest that these symptoms are not dependent on an intracoronary effect and that the mechanism whereby adenosine induces discomfort is more widespread. In particular, adenosine precisely reproduces the epigastric pain of duodenal ulcer in patients with this condition. $^{3}$

Dr Sylvén and colleagues assume that the angina-like pain was not in fact due to myocardial ischaemia. We agree. We studied the effects of intravenous adenosine, given at cardiac catheterisation with heart rate held constant during the investigation of patients for chest pain subsequently shown not to be associated with any cardiovascular abnormality; adenosine doubled coronary flow without increasing inotropic state or systolic tension.

A caveat - we believe that the dose of adenosine should be titrated with care, particularly when given in the presence of dipyridamole, as in the case of one of our patients who developed severe

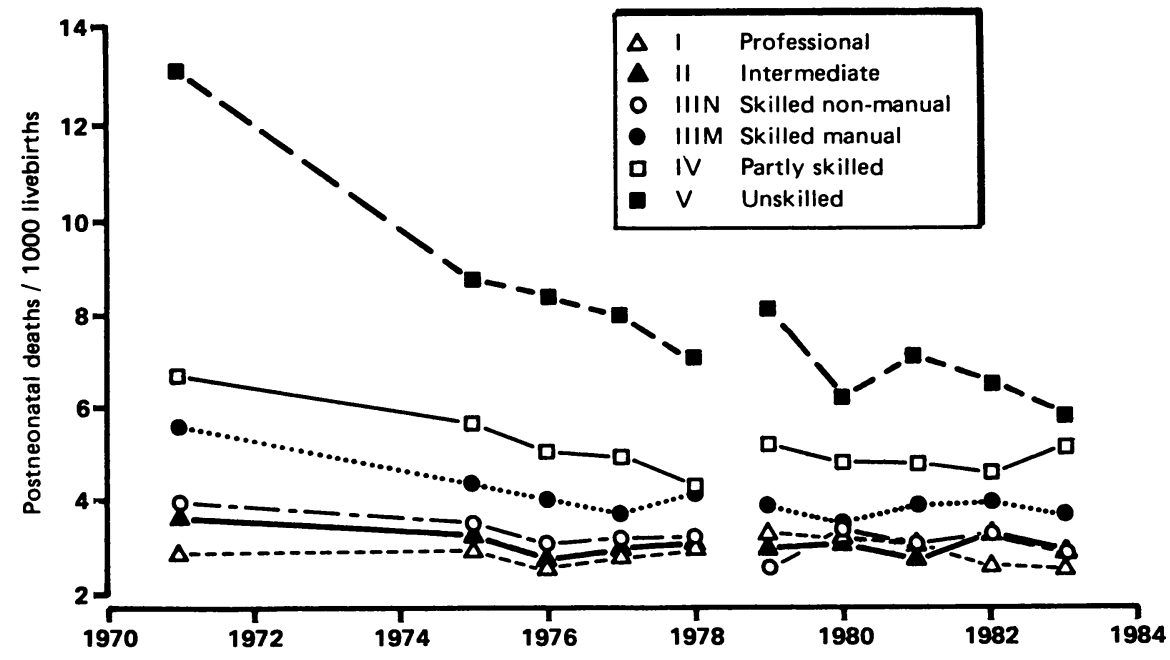

Source: OPCS Decennial Supplement $1970-2^{2}$ and mortality statistics DH3 (various years). 
bradycardia with $2.4 \mathrm{mg}$ adenosine given for supraventricular tachycardia. ${ }^{5}$

Department of Pharmacology and Therapeutics

ANDREW H WATT

PeTER G ReID

Philip RoutledGe

H SINGH

W J PENNY

Department of Cardiology,

A H HENDERSON

University of Wales College of Medicine,

Cardiff CF4 4XN

1 Watt AH, Reid PG, Stephens MR, Routledge PA. Adenosineinduced respiratory stimulation depends on site of infusion. induced respiratory stimulation depends on site of infusion
Evidence for an action on the carotid body? $\mathrm{Br} \mathcal{7}$ Clin Evidence for an actiol (in press)
Pharmate

2 Klabunde R. Dipyridamole inhibition of adenosine metabolism in human blood. Eur f Pharmacol 1983;93:21-6.

3 Watt AH, Lewis DJM, Horne JJ, Smith PM. Intravenous adenosine reproduces peptic ulcer pain in patients with recently symptomatic duodenal ulcer. Pflügers Arch 1986;407 (suppl 1):S40.

4 Watt AH, Singh H, Penny WJ. The effect of adenosine on coronary flow and left ventricular function in man. Pflugers Arch 1986;407 (suppl 1):S54.

Watt AH, Bernard MS, Webster J, Passani SL, Stephens MR Routledge PA. Intravenous adenosine in the treatment of supraventricular tachycardia: a dose-ranging study and interaction with dipyridamole. $\mathrm{Br}$ f Clin Pharmacol 1986;21: 227-30.

SIR,-We were interested to read the report by Dr Christer Sylvén and colleagues (26 July, p 227) of angina-like pain after bolus injections of adenosine in normal subjects.

We have recently studied the symptoms and cardiorespiratory effects of over 40 adenosine infusions in nine normal subjects. With its plasma half life of about 10 seconds $^{1}$ steady state plasma concentrations of adenosine can quickly be achieved. Adenosine was infused for at least five minutes in doses ranging from 40 to $120 \mu \mathrm{g} / \mathrm{kg}$ $\mathrm{min}$ and caused dose related increases in pulse rate and resting ventilation without changes in systemic blood pressure. ${ }^{23}$ During these infusions symptoms of anxiety, chest and abdominal discomfort, backache, jaw ache, and headache developed at infusion rates above $80 \mu \mathrm{g} / \mathrm{kg} / \mathrm{min}$, and their severity was thereafter dose related. These symptoms and the tachycardia were the factors that limited the higher infusion rates. Characteristic of the symptoms was their colicky nature, lasting for $30-45$ seconds and occurring at intervals of 45 to 120 seconds. Other than tachycardia there were no abnormalities on simultaneous electrocardiographic records at any infusion rate.

Six of these subjects were given $60 \%$ oxygen or air to breathe in a single blind manner during adenosine infusion. Oxygen reduced both the cardiorespiratory stimulation and the symptoms caused by adenosine. In these six subjects the effects of adenosine were compared before and after intravenous theophylline or a saline placebo (given randomised and double blind; mean plasma theophylline levels 9.5 (SD 0.9 ) $\mathrm{mg} / \mathrm{l}$ ). Theophylline reduced both the cardiorespiratory and symptomatic effects of adenosine when given by infusion, as Dr Sylvén and colleagues found with injections of adenosine (although it is unfortunate that they did not compare the effects of theophylline with those of a placebo).

Adenosine infusion therefore establishes an important characteristic of the symptoms caused by this nucleoside which studies of bolus doses could not reveal. The colicky nature of the symptoms, their reduction or disappearance with an increase in inspired $\mathrm{PO}_{2}$, and their reduction or absence after administration of theophylline raise doubts about the hypothesis of Dr Sylvén and colleagues that angina may be due to the stimulation of adenosine receptors. Angina is not classically colicky, and theophylline is not noted for its relief or prevention of angina. Although oxygen is used in the management of angina, it is given primarily to assist hypoxic myocardial tissue and is not always effective in relieving angina.

The protean manifestations of angina pectoris often make it a syndrome difficult to diagnose without the knowledge of other characteristics of the pain such as precipitating and relieving factors. Adenosine has widespread effects in the body and there are numerous receptors within the thorax that may cause pain. In certain circumstances adenosine may stimulate gastrointestinal smooth muscle ${ }^{4}$ and, as the authors implied, these symptoms of adenosine administration could equally be those of gastrointestinal pain. We feel that their recent hypothesis must remain in the realm of speculation

\section{Departments of Medicine}

and Clinical Pharmacology

Royal Postgraduate Medical School, London W120HS

P J BARNES

T-B CONRADSON

CM S Dixon

Department of Clinical Pharmacology,

D L MAXWELL

R W FULLER

Cardiothoracic Institute,

London SW 3

1 Klabunde RE. Dipvridamole inhibition of adenosine metabolism in human blood. Eur 7 Pharmacol 1983;93:21-6.

Barnes PJ, Conradson T-B, Dixon CMS, Fuller RW, Maxwell DL. Cardiorespiratory effects of adenosine infusion in man. f Phvsiol 1986;374:22.

Maxwell DL. Effect of adenosine infusion on resting ventilation in man. 7 Physiol 1986;374:23.

4 Gustaffson LE. Influence of adenosine on responses to vagal nerve stimulation in the anaesthetised rabbit. Acta Physiol Scand 1981;111:263.

\section{Opiate withdrawal: inpatient versus outpatient programmes}

SIR,-I would like to make the following observation on the paper by Dr Michael Glossop and colleagues (12 July, p 103).

The authors stated that "all (patients) were physically dependent on opiates," and that the mean dose of methadone "required for withdrawal" was $37 \cdot 5 \mathrm{mg} /$ day. No further information is given as to how physical dependence was determined or how the methadone requirement was calculated. In practice it is often found that little or no methadone is required to suppress any

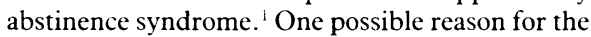
relative failure of the outpatient group might have been that some patients significantly increased their daily opiate intake over a prolonged period, thus engendering, rather than reducing, their dependence.

Secondly, the paper gives no indication of how long a period of abstinence was confirmed by urine analysis for the groups being compared. Fifty five per cent of the outpatient group remained in contact with the clinic, compared with $29 \%$ of the inpatient group. If one assumes that all those lost to follow up are using drugs again (the gloomiest, but most plausible, explanation) five weeks drug free as an inpatient would appear to be antitherapeutic for many patients.

Thirdly, urine analysis for drugs is notoriously unreliable. No mention is made of the authors' response to isolated positive findings in the absence of other evidence of drug use.

Finally, it seems disingenuous of the authors to compare their study with that of Edwards and Guthrie, as their paper is methodologically far less sophisticated. Edwards and Guthrie: $(a)$ excluded those of poor prognosis and those unwilling to be randomly entered to their trial; $(b)$ detoxified inpatients and outpatients over the same time period; $(c)$ mobilised community resources to help in treatment; $(d)$ followed up their sample for 12 months.
Failure to establish "neurophysiological dependence"; failure to randomise patients to treatment groups, using different withdrawal regimens for the two groups; and failure to provide significant psychosocial support for the outpatient group make it very hard to accept either the clinical or the policy implications of the study.

ANDREW MCBRIDE

\section{Whitchurch Hospital,}

Cardiff CF4 7XB

1 Jenner FA, Gill PV. Helping heroin addicts to kick the habit. BrMed f 1985;291:344.

AUTHORS' REPLY-Many of Dr McBride's criticisms appear to be due to a hasty reading of our paper since several are already answered in the text. Some of his points, however, are due to his misunderstanding the purpose of our study

Firstly, determining the presence of physical dependence and assessing the dose requirements for withdrawal are fundamental problems for all who are clinically involved with these issues. In the absence of any definitive or agreed procedures, repeated opiate positive urine results plus the presence of clinical signs and self report data were all of some use in these tasks. Further information on methods of determining dependence and establishing methadone requirements at this clinic are given elsewhere. ${ }^{1}$ The existence of the opiate withdrawal syndrome is well documented. It would be unfortunate if Dr McBride's suggestion was interpreted to mean that abrupt and unmodified withdrawal was an appropriate method of detoxifying opiate addicts. He suggests that the outpatient groups may have been using extra drugs without our knowledge. This would have been possible only if they had been using extra methadone, since any other opiate or non-opiate drug would have been detected by the urine analysis that was conducted at each clinic attendance. In any case additional drug use would have increased the failure rate for the outpatient programmes and would have reinforced rather than weakened our conclusions.

Secondly, Dr McBride appears to be confused about the aims of our study. This is clearly stated in the first sentence of the Discussion. We were comparing methods of getting opiate addicts off drugs. We were not looking at ways of preventing subsequent relapse. These two phases of treatment are known to be independent, ${ }^{2}$ and detoxification alone is known to be ineffective as a means of preventing relapse.

Thirdly, on what basis does Dr McBride assert that urine analysis for drugs is "notoriously unreliable"? The DHSS guidelines of good clinical practice state that urine analysis is a necessary and centrally important part of diagnosis. ${ }^{+}$Our own procedures, which require the passing of specimens under supervision, and analysis based on chromatographic methods backed up with the more sensitive glucuronidase hydrolysis, have always proved reliable. Perhaps Dr McBride could suggest a better objective means of detecting the use of drugs? Our results were not based solely on urine analysis but used other clinical data to suggest the use of drugs. Urine analysis was used as a confirmatory measure.

Finally, (a) our study clearly included subjects willing to be randomly allocated to the different treatment options and our results showed this not to have a significant effect (paragraph 2, Results); (b) the different time periods for the inpatient and outpatient programmes are discussed in both paragraph 2 of the Methods section and paragraph 4 of the Discussion; (c) our paper is obviously not intended to challenge the findings of Edwards and Guthrie. ${ }^{5}$ We refer to that important 